\title{
ELASTIC PROPERTIES OF SILICA AEROGELS FROM A NEW RAPID SUPERCRITICAL EXTRACTION PROCESS
}

\author{
Joachim Gross \\ Paul R. Coronado \\ Lucy M. Hair \\ Lawrence W. Hrubesh
}

This paper was prepared for submittal to the

5th International Symposium on Aerogels

Montpellier, France

September 8-11, 1997

August 11, 1997

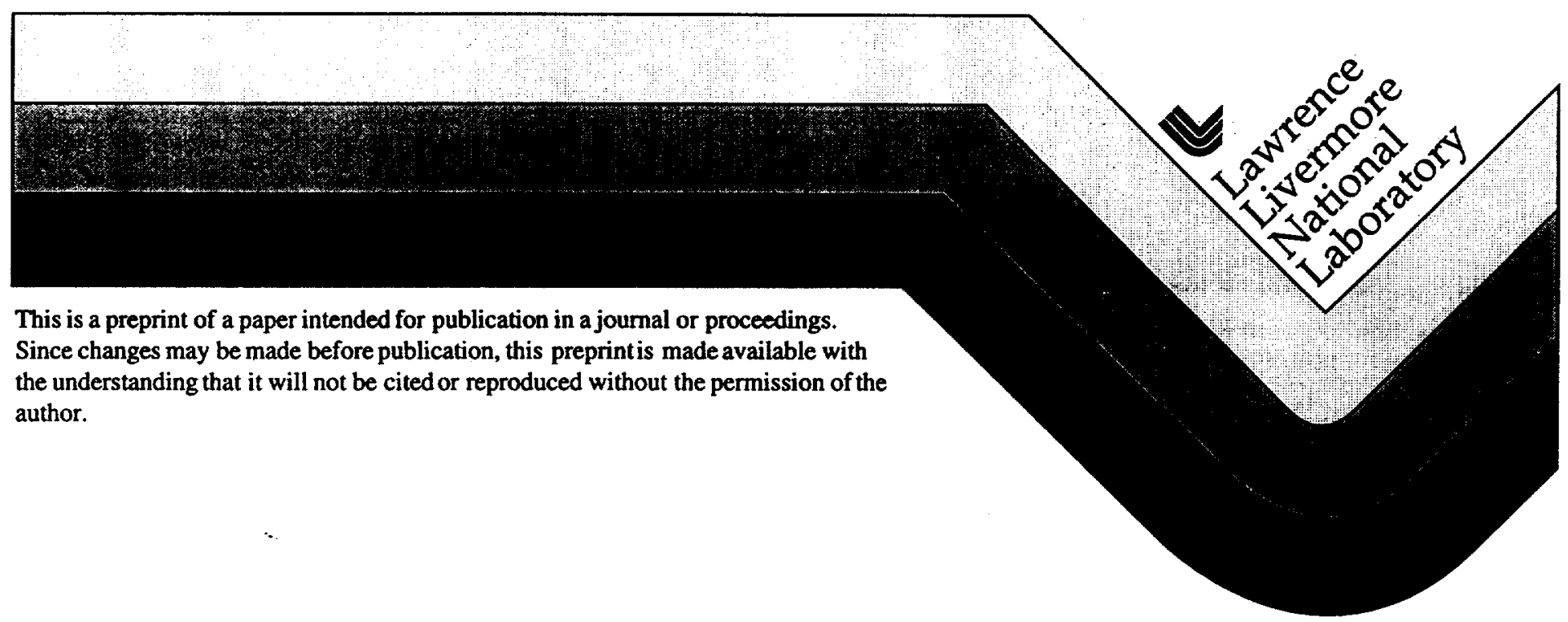




\section{DISCLAIMER}

This document was prepared as an account of work sponsored by an agency of the United States Government. Neither the United States Government nor the University of California nor any of their employses, makes any warranty, express or implied, or assumes any legal liability or responsibility for the accuracy, completeness, or usefulness of any information, apparatus, product, or process disclosed, or represents that its use would not infringe privately owned rights. Reference herein to any specific commercial product, process, or service by trade name, trademark, manufacturer, or otherwise, does not necessarily constitute or imply its endorsement, recommendation, or favoring by the United States Government or the University of California. The views and opinions of authors expressed herein do not necessarily state or reflect those of the United States Government or the University of California, and shall not be used for advertising or product endorsement purposes. 


\section{Elastic Properties of Silica Aerogels from a New Rapid Supercritical Extraction Process*}

Joachim Gross ${ }^{\text {a }}$, Paul R. Coronado, Lucy M. Hair and Lawrence W. Hrubesh

Lawrence Livermore National Laboratory, P.O. Box 808, L-322, Livermore, CA 94550, USA

new address: Princeton University, Dept. of Civil Engineering and Operations Research, Eng. Quad E-228, Princeton, NJ 08544, USA

* Work performed under the auspices of the U.S. Department of Energy by the Lawrence Livermore National Laboratory under Contract No. W-7405-ENG-48.

\section{Abstract:}

Silica aerogels were produced by a new process from Tetramethoxysilane (TMOS) with ammonia as base catalyst. The process involves pouring the liquid sol in a stainless steel mold and immediately heating it to supercritical conditions. Gelation and aging occurs during heating and reaction rates are high due to high average temperatures. The gel fills the container completely, which enables relatively fast venting of the supercritical fluid by providing a constraint for swelling and failure of the gel monolith. The whole process can be completed in $6 \mathrm{~h}$ or less.

Longitudinal and shear moduli were measured in the dried aerogels by ultrasonic velocity measurements both as a function of chemical composition of the original sol and of position in the aerogel. It was found that the sound velocity exhibits marked maxima on the surface of the cylindrical specimens and specifically close to the ends, where the fluid left during venting. Specimens with high catalyst concentration and high water:TMOS ratio exhibited higher average moduli.

\section{Introduction}

One of the key problems for using aerogels in commercial applications is their relatively high cost. At the moment, the supercritical drying process is a severe obstacle in reducing the production price of aerogels. Several methods have been devised to circumvent this problem. Freeze drying [1] did not yet lead to monolithic specimens. Subcritical drying of gels with chemically modified internal surfaces was successfully used to produce monolithic samples of relatively low densities [2], however the process involves timeconsuming solvent exchange steps. At Lawrence Livermore National Laboratory (LLNL) a process was recently reported that allowed for gelation, aging and drying to occur all in a single step [3]. This method uses a near net shape mold made of steel. The reactants are mixed and poured into the mold, the mold is closed with a metal-metal seal capable of opening slightly under high pressure. During rapid heating of the mold in a pressure vessel the liquid mixture expands and is partially vented. Due to the relatively high average temperatures in the mold, gelation and aging occur within minutes and the gel completely fills the container. After reaching supercritical conditions, the pressure vessel is depressurized. Most of the supercritical fluid leaves the mold because of its low viscosity, 
which facilitates flow even through small leaks in the metal-metal seal. After cooling to ambient temperature, the mold is opened and the aerogel monolith is removed. The complete process, from mixing the reactants to retrieving the aerogel, can be completed in less than $6 \mathrm{~h}$, and times as short as $1 \mathrm{~h}$ have been achieved.

This work is dedicated to elastic characterization of aerogels produced in the Rapid Supercritical Extraction (RSCE) process. We will demonstrate the effects of chemical composition of the starting sol (water and catalyst concentrations) and determine inhomogeneities induced by the process.

\section{Experimental}

Silica aerogels were produced from mixtures of methanol, water, tetramethoxysilane (TMOS) and ammonium hydroxide $\left(\mathrm{NH}_{4} \mathrm{OH}\right)$ as catalyst using the RSCE process. The standard composition was $\left[\mathrm{H}_{2} \mathrm{O}\right]:\left[\mathrm{NH}_{4} \mathrm{OH}\right]:[\mathrm{MeOH}]:[\mathrm{TMOS}]=3.12: 0.0014: 10.4: 1$. Starting form this composition, three series of samples were prepared, one varying the amount of water, and two with varying catalyst amount; the last series used half the amount of methanol to increase the density of the samples. Our samples were cylinders with $30 \mathrm{~mm}$ diameter and $25 \mathrm{~mm}$ height. The apparent density was measured to an accuracy of $1 \%$ by weighing and measuring the dimensions with a caliper. Elastic moduli were calculated from measured longitudinal and shear sound velocities according to $c_{i i}=c^{2} \rho-p$, where $\mathrm{ii}=11$ for the longitudinal modulus and $\mathrm{i}=44$ for the shear modulus, $c$ is the appropriate sound velocity and $\rho$ is the density of the sample. The ambient air pressure $p$ is subtracted in order to correct for the air in the pores [4]. The accuracy of the elastic moduli was estimated from the accuracy of the travel time and ranges from 1 to $5 \%$, depending on the quality of the sound signal obtained. In order to detect possible inhomogeneities in the samples, longitudinal sound velocity measurements were made as a function of position in the sample as follows: From the end of the samples three circular slices were cut with a saw. The slices were mounted in cardboard frames with drops of polyurethane adhesive and attached to a support capable of moving in the plane of the slices. Ultrasonic transducers with a center frequency of $180 \mathrm{kHz}$ were fitted with Plexiglas cones of $1 \mathrm{~mm}$ tip diameter, one being used as transmitter, the other as receiver. The tips of the cones were brought into contact with the sample slices from opposite sides at various locations and the sound velocity was determined.

\section{Results}

Fig. 1 shows a $\log -\log$ plot of the longitudinal modulus $c_{11}$ as function of density $\rho$ for the three series of samples produced. For comparison, silica aerogels produced in conventional way are added [5]. In Fig. $2 \mathrm{c}_{11}$ is plotted as a function of the [ $\left.\mathrm{H}_{2} \mathrm{O}\right]$ :[TMOS] ratio. Comparison to Fig. 1 shows that the samples with the higher water content are comparable in modulus to standard silica aerogels, whereas below a water to monomer ratio of 4 the RSCE aerogels are a factor of 6 weaker. The latter samples are opaque while intermediate water concentrations lead to clear gels. Only at $\left[\mathrm{H}_{2} \mathrm{O}\right]:[\mathrm{TMOS}]=19$ do the samples turn opaque again and also show considerable shrinkage. The modulus and density of specimens from the series with varying catalyst amounts are plotted in Fig. 3. As expected, an increased amount of catalyst stiffens the aerogels considerably. An order of magnitude in modulus is covered by the variation in ammonia catalyst. In addition, however, the density of the samples exhibits an increase of about $20 \%$ with increasing $\left[\mathrm{NH}_{4} \mathrm{OH}\right]:[\mathrm{TMOS}]$. The appearance of the samples is milky for low catalyst concentrations. The standard composition on the aerogels are clear with a slight haze that 
progressively disappears with increasing catalyst amount. Comparison of Figs. 1 and 3 again reveals that the samples with highest catalyst amounts are about as stiff as standard silica aerogels at the same density. Fig. 4 shows the result of a position dependent sound velocity measurement along the diameter of three slices cut from the ends of an aerogel sample. The elastic modulus could not be determined as a function of position because the local density is unknown. It can still be seen, however, that the variation in local properties is very large, specifically in the endcap of the sample. The inset gives a sketch of the mold and the slicing pattern. Note the steel lids that are bolted to the cylindrical body, providing for two annular leaks for drainage of the fluid. In additional measurements not shown here it was noticed that the sound velocity also varies strongly along the perimeter of the samples. The maximum sound velocity is reached at the perimeter of the endcap. However, for the other two slices the maximum seems to move towards the axis by up to $2 \mathrm{~mm}$. Note also that the velocities at the axis sort in reverse order as compared to the perimeter: The endcap has the lowest, the third slice the highest center sound velocity. Finally, in Fig. 5 the sound velocities along the diameter of the endcaps of three different aerogels are compared. One was allowed to gel in the mold at room temperature and then subjected to the heating and drying cycle, the second was heated with a rate of $2.3^{\circ} \mathrm{C} / \mathrm{min}$ and the third was heated at $4.6{ }^{\circ} \mathrm{C} / \mathrm{min}$ and is the one depicted in Fig. 4. The pregelled sample exhibits only very little variation, but it does follow the same pattern as the other ones. The samples gelled during heating show similar behavior, but the one heated slowly only has about half as much variation as the one heated fast. The difference in shape between the curves is not systematic but is rather due to annular variations in properties.

\section{Discussion}

As can be seen from Fig. 1 the aerogels produced using the RSCE process have similar elastic properties as standard silica aerogels if the parameters are chosen accordingly. However, they can also be up to an order of magnitude weaker at low catalyst or water concentration.

The step in modulus as the [ $\left.\mathrm{H}_{2} \mathrm{O}\right]$ :[TMOS] ratio exceeds 4 as seen in Fig. 2 is not unexpected. 4 moles of water are required to fully hydrolyze the TMOS monomer, if less water is used the crosslinking can still be complete, but the reaction rate is slower because the hydrolysis depends on the condensation reaction to set free more water. Note however, that these arguments rely on the assumption that hydrolysis and condensation reactions occur homogeneously. This is not the complete truth since part of the monomers could remain in their original esterified state while others hydrolyze and build a gel. The fact that aerogels could be produced with less than 2 moles of water per mole of TEOS with the RSCE process shows that this actually happens; however, the resulting gels are extremely fragile and were not included in this study. If the water content of the pore liquid becomes too high, supercritical conditions are not reached any more during the process and the gels shrink due to capillary forces. This is observed for the gels made with a ratio of 19 . It seems that for this process a [ $\left.\mathrm{H}_{2} \mathrm{O}\right]:[\mathrm{TMOS}]$ ratio of 5 to 10 is optimal.

The variation of catalyst concentration results in a more gradual change of properties, as seen in Fig. 3. The fact on density is interesting because it is opposite of what is observed in standard silica aerogels. There, higher stiffness due to more catalyst leads to less shrinkage during drying, which in turn causes the density to decrease. In the RSCE process the gel is constantly under internal pressure during heating because the pore fluid expands faster than the gel skeleton, pressing the gel to the mold; therefore the RSCE process results in no shrinkage during drying. Rather, increased catalyst amounts cause the 
gel to form sooner in the process. Once the gel is formed, a pore fluid depleted of monomers and small clusters drains through the metal seal during further heating. This minimizes the loss of silica and leads to a higher density as compared to low catalyst samples, where more monomer can escape prior to gelation. A measure for the gel time has actually been determined using a modified mold with a series of thermocouples at various locations in the gel. Prior to gelation, the temperature is fairly homogeneous due to convection currents inside the mold. Once the viscosity of the gel becomes too high for the heat flow to be carried by convection, the surface of the gel heats faster than the interior. The transition appears to occur rather rapidly within a minute or so. For a gel heated at 10 ${ }^{\circ} \mathrm{C} /$ min convection typically stops at about $70^{\circ} \mathrm{C}$ or after $7 \mathrm{~min}$. Gelation can be assumed to occur shortly afterward.

The variation of sound velocity within the gels can be explained as follows. As mentioned above, initially the fluid heats homogeneously. As soon as temperature differences start to build up, however, the reaction rates also vary. Thus the gel presumably forms and ages faster at the perimeter, causing enhanced stiffness and therefore higher sound velocities. This effect is rather weak for the pregelled sample shown in Fig. 5 because only aging is affected; the higher the heating rate in the other two samples, the higher the temperature differences and therefore the effect on the stiffness. However, the higher heating rates at the surface of the container also cause the liquid there to expand faster than at the interior. Consequently, some flow occurs away from the walls and then toward the endcaps, where the leaks allow for drainage of some of the excess liquid. Because the gel is still susceptible to viscous deformation and some silica in the form of monomers and small clusters can take part in the flow, the density of the gel network ends up to be slightly lower in the vicinity of the surface but greatly enhanced close to the leaks along the perimeter. This causes the sound velocity to exhibit a slight maximum away from the surface as seen for the two inner slices in Fig. 4 and also the reverse order of sound velocity at the axis. Close to the leaks, however, the flow rates are rather high and therefore a dramatic increase in density occurs as seen in the higher sound velocity. Since the leakage occurs with varying rate along the perimeter, the properties of the gel are not rotationally symmetric. Also, higher heating rates cause a higher flow rate and more transport of poorly crosslinked material from the center of the sample; this causes the rapidly heated gel to be more inhomogeneous than the others.

For most applications, those inhomogeneities are counterproductive, so it is of interest to try and avoid them as far as possible. The mechanisms discussed above provide a handle to achieve more homogeneous aerogels. Obviously, it would be beneficial to have no drainage of liquid and as little as possible temperature gradient after the gel point. To achieve this, it would be necessary to have gelation occur as close to supercritical conditions as possible. A very high heating rate would possibly be one way to achieve this; alternatively, one could introduce an isothermal gelation period and, after some aging and stiffening has occurred, continue to heat to supercritical conditions. In any case by adjusting the amount of precursor poured into the mold one would have to minimize drainage of liquid. The goal would be to use just enough liquid to fill the mold completely after it was heated to the gelation temperature. If subsequent heating is necessary, the mold should be able to sustain the pressure buildup without draining large amounts of liquid. 


\section{Conclusions}

It was shown in this paper that the RSCE process leads to silica aerogels comparable in many aspects to their conventionally dried counterparts. In some respects, however, there are marked differences related to the fact that the gels are strictly confined during gelation, aging and drying. An unwelcome side effect of the new process is the inhomogeneity introduced to the samples by inhomogeneous heating and drainage of liquid. It is believed, however, that these deficiencies can be overcome by moving the gelation closer to supercritical conditions, not filling the mold completely and introducing an isothermal step during gelation. Further research will be necessary to understand the effects of these fundamental changes to the gelation process. Among others, a different interaction between monomers and clusters on one side and the now supercritical solvent on the other side can be expected, with profound influence on the structure and properties of the resulting aerogels. 


\section{Figure captions}

Fig. 1 Overview of longitudinal elastic modulus of samples examined in this work as function of density. Values for standard silica aerogels are added for comparison [5].

Fig. 2 Elastic modulus as function of water:monomer ratio (called $\mathrm{H}_{2} \mathrm{O}$ series in Fig. 1)

Fig. 3 Elastic modulus (open squares) and density (full squares) as function of the catalyst to monomer ratio $\left(\mathrm{NH}_{4} \mathrm{OH}\right.$ series 1$)$.

Fig. 4 Position dependent sound velocity along the diameter of slices cut from a sample heated at $4.6^{\circ} \mathrm{C} / \mathrm{min}$. The inset sketches the mold and the position of the cuts. Sound velocities were measured parallel to the cylinder axis (vertical in the sketch). The size of the symbols approximately indicates the tip diameter of the ultrasonic probe used.

Fig. 5 Position dependent sound velocities along the diameter of the endcaps cut off three different samples. The fast heated sample corresponds to the one shown by circles in Fig. 4.

\section{Key words}

elastic modulus, silica aerogels, supercritical drying, sound velocity, inhomogeneity

\section{References}

[1] G.W.Scherer, J. Non-Cryst. Solids 155 (1993) 1.

[2] D.M.Smith, D.Stein, J.M.Anderson, W.Ackerman, J. Non-Cryst. Solids 186 (1995) 104.

[3] J.F.Poco, P.R.Coronado, R.W.Pekala, L.W.Hrubesh, Mat. Res. Soc. Symp. Proc. 431 (1996) 297.

[4] J.Gross, J.Fricke, L.W.Hrubesh, J. Acoust. Soc. Am. 91 (1992) 2004.

[5] J.Gross, T.Schlief, J.Fricke, Mat. Sci. Eng. A168 (1993) 235. 
Fig 1

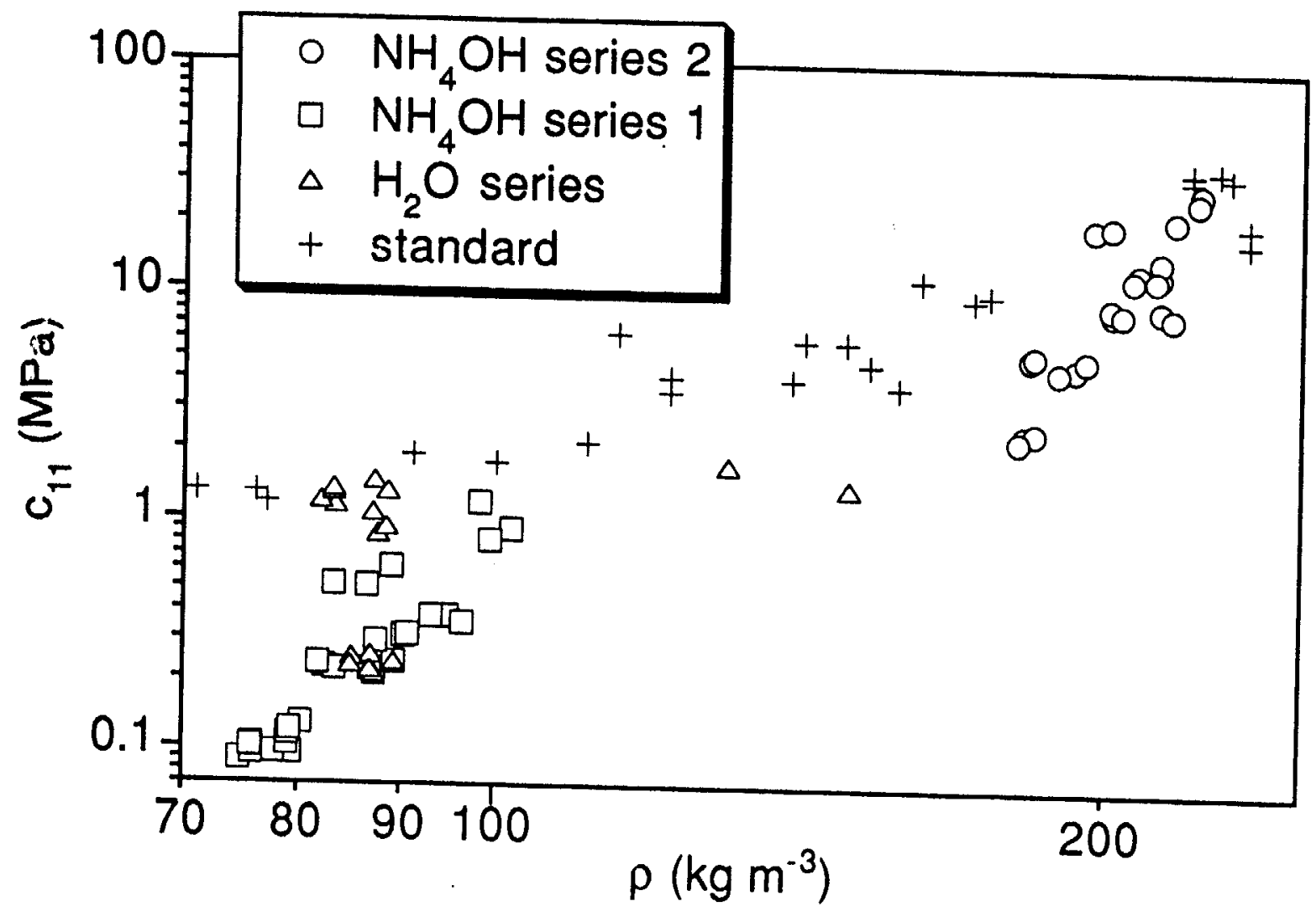


Fig 2

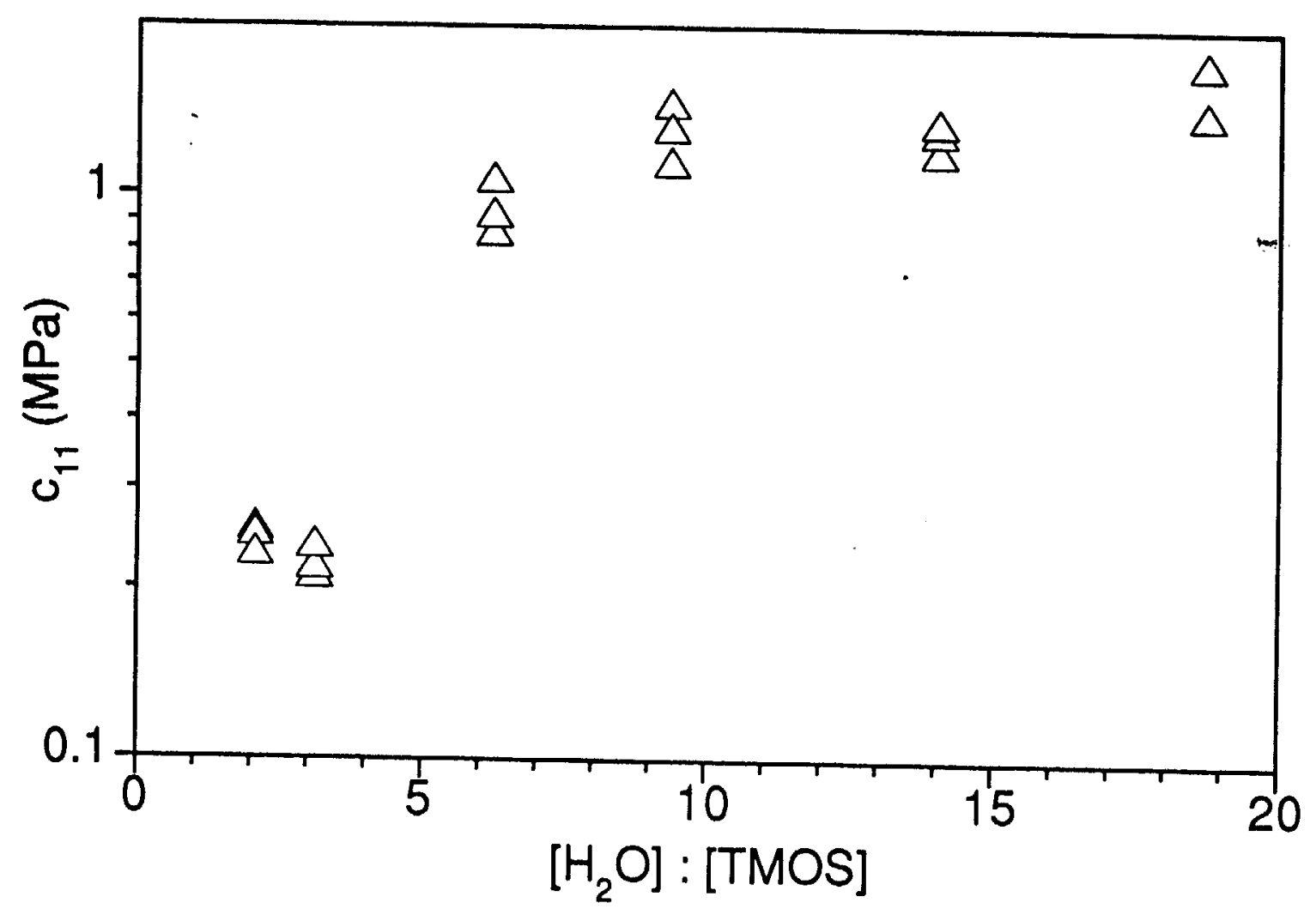


Fig 3

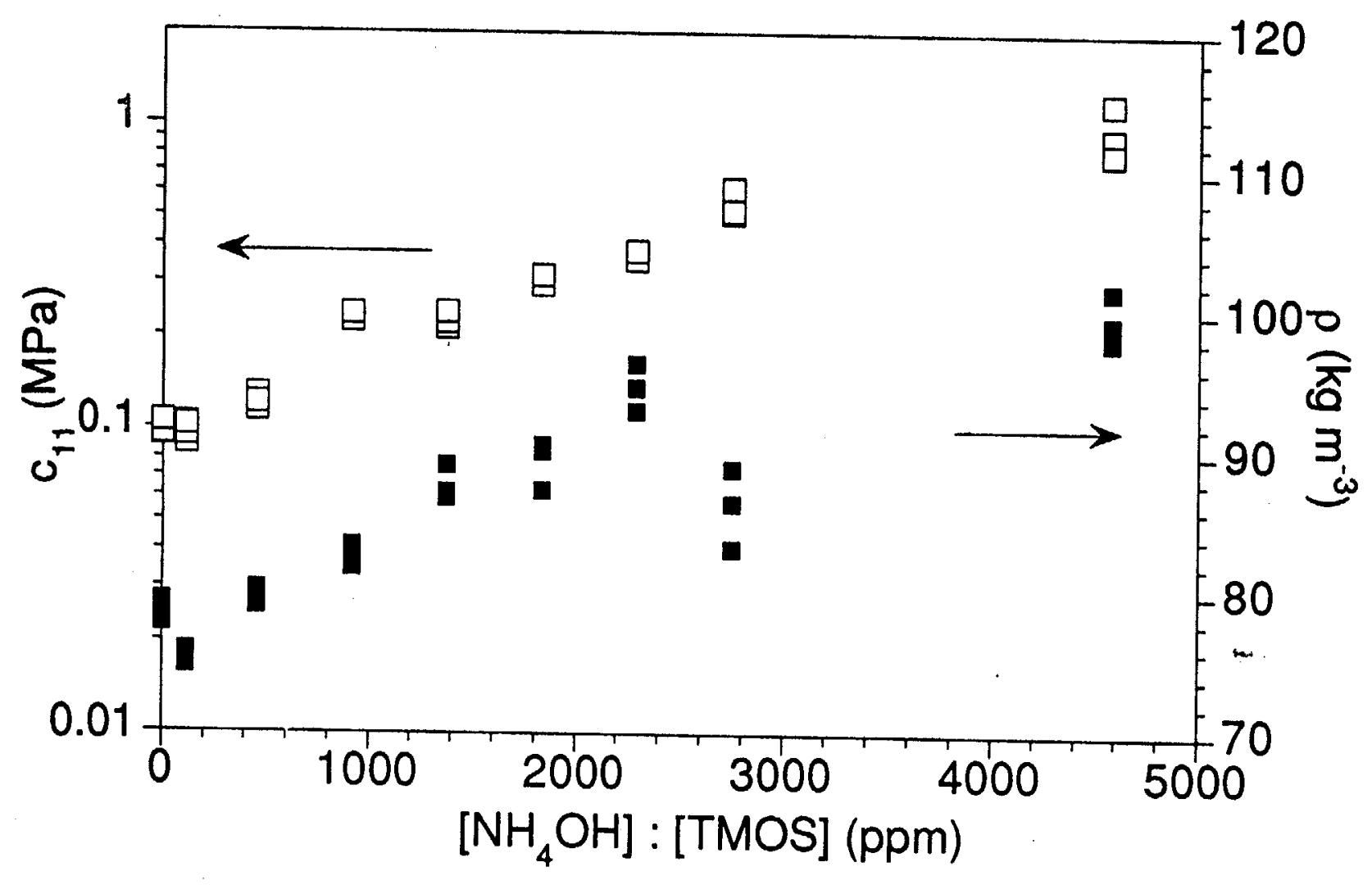


Fig 4

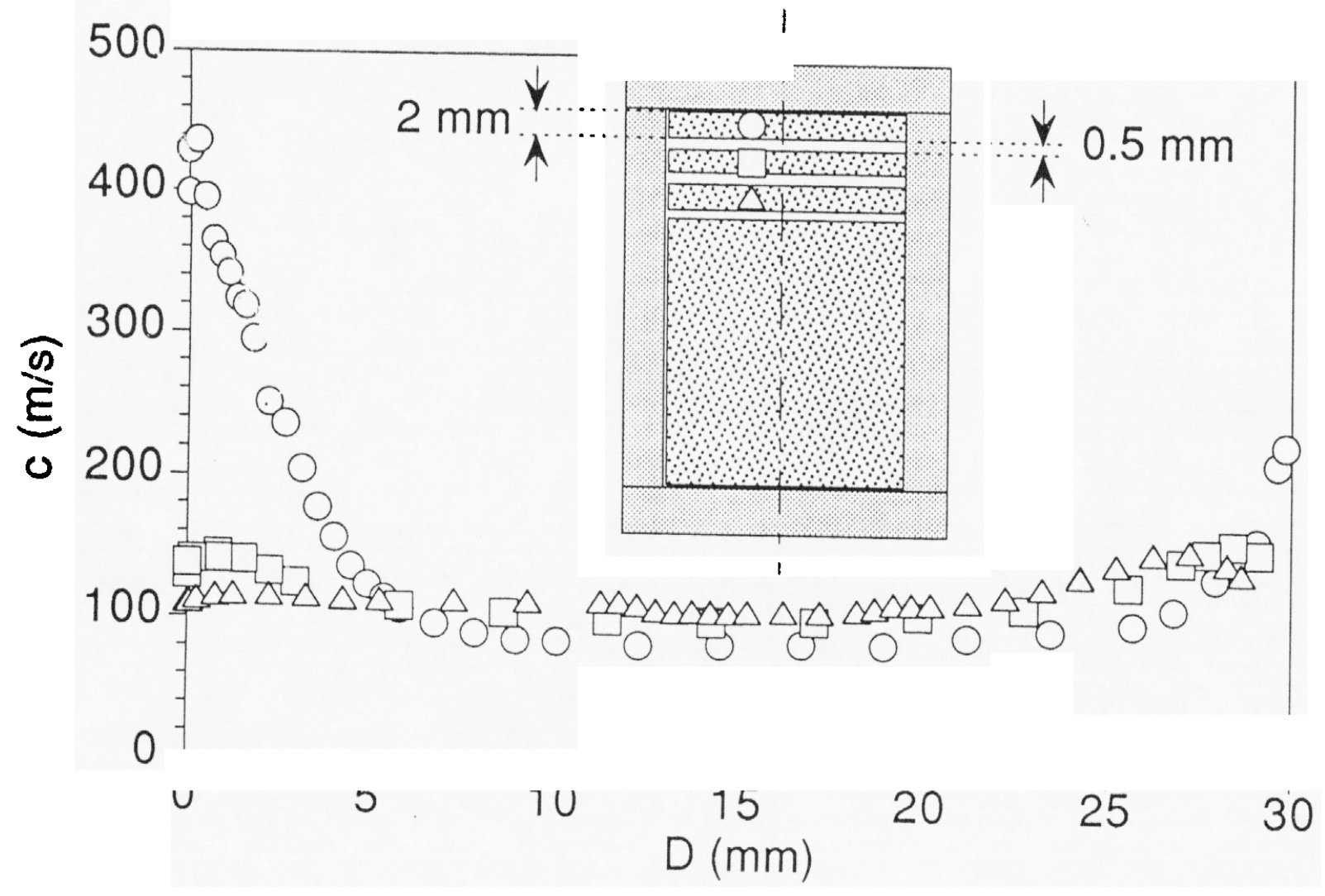


Fig 5

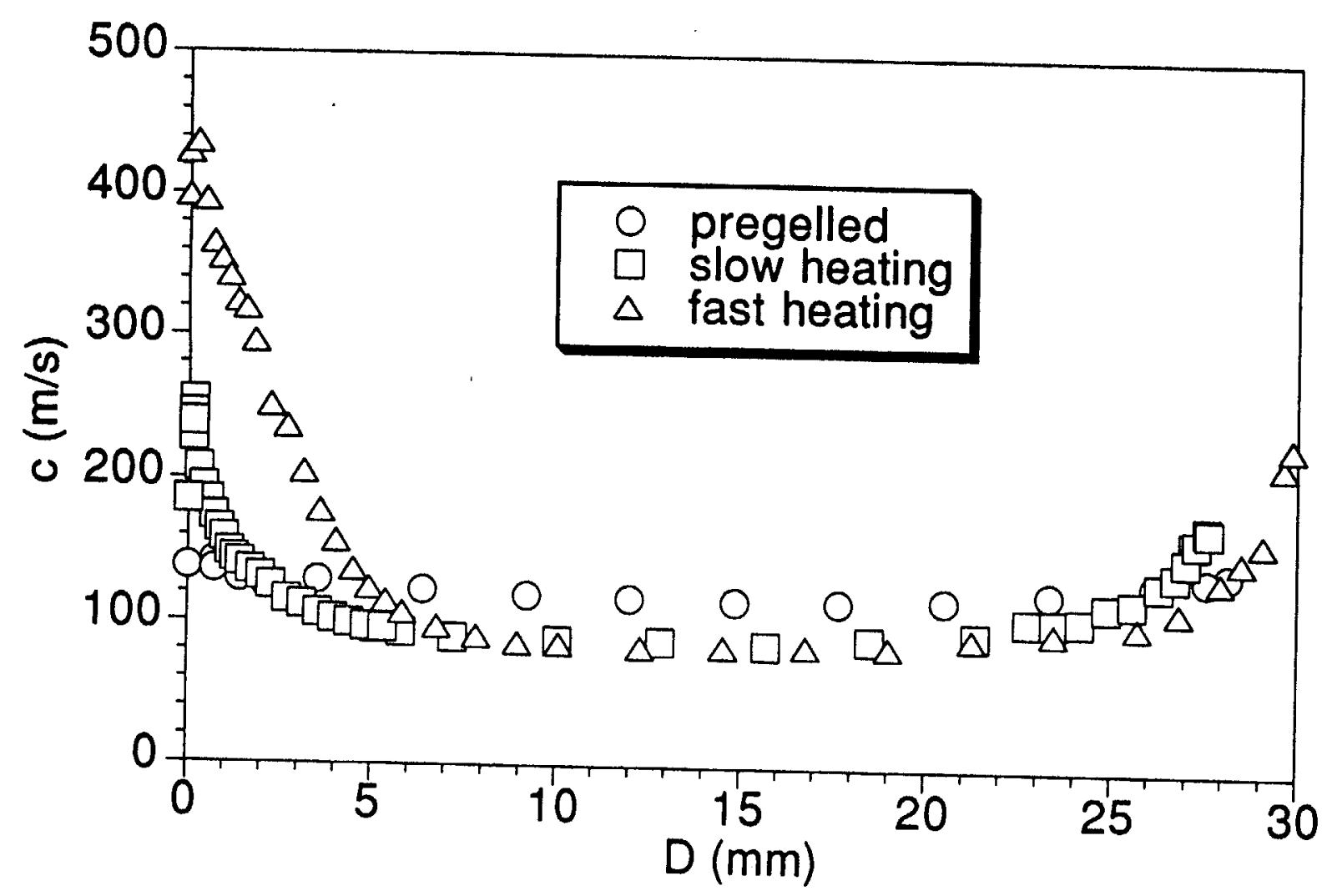





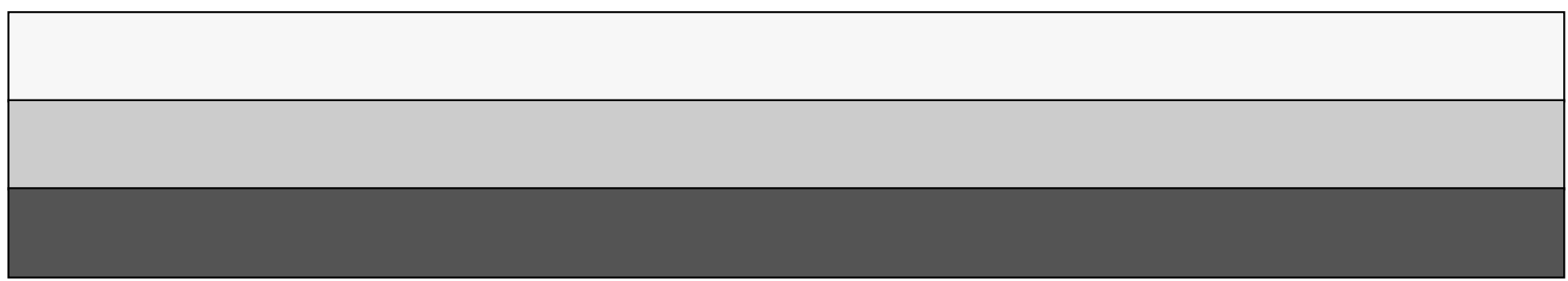

